\title{
Carcinoma en cuirasse
}

\author{
Ashlee L. Culver, BS ${ }^{\mathrm{a}}$, David M. Metter, $\mathrm{MD}^{\mathrm{b}} \mathbb{D}$, and John E. Pippen, Jr., MD ${ }^{\mathrm{a}, \mathrm{c}, \mathrm{d}}$ (D)
}

${ }^{a}$ Department of Medicine, Texas A\&M Health Sciences Center, Dallas, Texas; ${ }^{b}$ Department of Pathology, Baylor University Medical Center at Dallas, Dallas, Texas; 'Baylor Charles A. Sammons Cancer Center, Baylor University Medical Center at Dallas, Dallas, Texas; ${ }^{\mathrm{d} T e x a s}$ Oncology, Dallas, Texas

\section{ABSTRACT}

Carcinoma en cuirasse $(\mathrm{CeC})$ is an extremely rare form of cutaneous metastasis of breast cancer. Guidelines for diagnosis and treatment of $\mathrm{CeC}$ are limited due to the small number of reported cases. It can be difficult to distinguish $\mathrm{CeC}$ from benign etiologies on initial presentation, but $\mathrm{CeC}$ can be easily distinguished by histopathology. Treatment of $\mathrm{CeC}$ focuses on palliation with no consensus on therapy guidelines. Treatment modalities that have been explored include chemotherapy, radiotherapy (with or without local hyperthermia), and hormonal antagonists. Here we present a 62-year-old woman with recurrent triple-negative breast cancer manifesting as CeC to the chest wall.

KEYWORDS Breast cancer; carcinoma en cuirasse; cutaneous metastasis

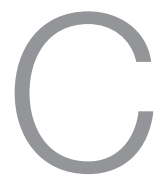

arcinoma en cuirasse $(\mathrm{CeC})$ is a rare form of breast cancer metastasis, with an incidence of approximately $6 \% .{ }^{1}$ It tends to appear after initial treatment, ${ }^{2}$ and skin metastases are often associated with breast carcinomas in women. ${ }^{3} \mathrm{CeC}$ first appears as nodules that coalesce, forming diffuse sclerodermoid indurations invading the chest wall and abdomen. ${ }^{4,5}$ Anatomist Alfred Velpeau used the term cuirasse, because he thought that the clinical presentation resembled a medieval breastplate or a cuirass. ${ }^{6}$ Due to the small number of documented cases, data on this disease are limited. This makes distinguishing $\mathrm{CeC}$ from a rash or other forms of cutaneous metastases difficult. Here we report a case of a patient who developed $\mathrm{CeC}$ and discuss her progression on treatment.

\section{CASE REPORT}

A 62-year-old black woman presented in August 2015 with a mass in the right breast that had been growing for a month. She was nulliparous with a 30-pack-year smoking history and a family history of breast cancer, including a niece with a BRCA1 gene mutation. A diagnosis of grade III triple-negative infiltrating ductal carcinoma was made. She received several cycles of dose-dense chemotherapy followed by bilateral mastectomy and lymph node dissection; 10 of 13 lymph nodes had disease present. Upon completion of radioand chemotherapy, she began breast reconstruction 6 months postmastectomy. In September 2016, she developed a pruritic, erythematous, nodular rash bilaterally over her chest wall. A punch biopsy showed a 7-mm focus of high-grade invasive ductal carcinoma in the dermis similar to the prior tumor. The current tumor had large, pleomorphic, atypical cells with increased nuclear-to-cytoplasmic ratios; large prominent nucleoli; open chromatin; cytoplasmic vacuoles; and scattered karyorrhectic debris, with many mitotic figures, like the original tumor (Figure 1a). Bone and computed tomography scans of the chest, abdomen, and pelvis showed no distant disease, only disease in the chest wall and lymph nodes. She received palliative treatment with carboplatin and gemcitabine, but her cancer progressed and became $\mathrm{CeC}$. The chest wall and abdomen were diffusely indurated with firm nodules coalescing into diffuse sclerodermoid plaques (Figure 1b). They were hyperpigmented in a background of erythema (Figure 1b). After poor response to the first palliative treatment, she began another regimen with eribulin, which softened her hard nodules. Progress stagnated after five treatment cycles. She switched to liposomal doxorubicin but the cancer progressed. She lived 20 months with CeC.

Corresponding author: John Pippen, Jr., MD, The Baylor Charles A. Sammons Cancer Center, 3410 Worth St., Suite 400, Dallas, TX 75246 (e-mail: John.Pippen@USOncology.com)

Color versions of one or more of the figures in this article can be found online at www.tandfonline.com/ubmc.

Received November 1, 2018; Revised December 18, 2018; Accepted December 26, 2018. 


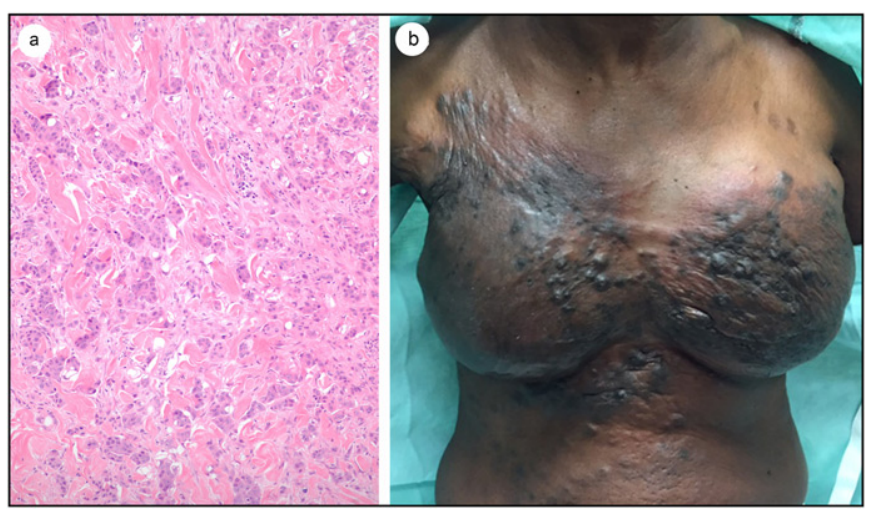

Figure 1. (a) Hematoxylin and eosin-stained section of the tumor in the reticular dermis of the skin ( $\times 100$ magnification). (b) Clinical appearance of recurrence of triple-negative breast cancer patient. There are cutaneous metastases to the skin overlying the breast skin, with extensive purple to black nodularity with diffuse sclerodermoid indurations.

\section{DISCUSSION}

Breast cancer is not only the most common malignancy in women ${ }^{7}$ but is the primary tumor in about $70 \%$ of cutaneous metastases. ${ }^{8,9}$ Cutaneous disease may be the first presentation, because widespread internal metastases can accompany cutaneous disease, resulting in a poor prognosis of only months. ${ }^{10}$ This differs with cutaneous metastases in breast cancer patients, because median survival was 13.8 months with a 3.1\% 10-year survival rate. ${ }^{11}$ Despite the extensive cutaneous involvement, our patient had only local disease but died 20 months after her rash developed.

$\mathrm{CeC}$ comprises $3 \%$ to $6 \%$ of cutaneous metastases in breast cancer patients. ${ }^{12} \mathrm{CeC}$ presents clinically in two stages. The first is erythema and pitting edema of the skin, often confused with a benign dermatitis. Next is formation of thick leathery skin that hardens. ${ }^{5}$ Sclerodermoid chest wall metastases like $\mathrm{CeC}$ have a distinctive histologic appearance with fibrotic stroma formed secondary to tumor deposition. ${ }^{3}$ Eventually, this fibrosis overtakes the area, leaving few identifiable tumor cells. Tumor cells present are often seen in an "Indian-filing" pattern with cells lined up in single rows within collagen bundles of the dermis. ${ }^{13}$ The presence of fibrosis makes it difficult for chemotherapy to penetrate and be effective. ${ }^{14}$

The differential diagnosis for patients with $\mathrm{CeC}$ includes radiation-induced morphea, inflammatory breast cancer, radiation dermatitis, and other cutaneous metastases. These can be discerned by histology, which often resembles the primary cancer. Unlike radiation dermatitis and inflammatory breast cancer, after the original stage $\mathrm{CeC}$ is not associated with inflammatory changes. ${ }^{15}$ Morphea and postirradiation morphea grossly resemble $\mathrm{CeC}$, but sclerosis in morphea is characterized by thickened collagen bundles, decreased fat and vascularity, and atrophic eccrine glands. ${ }^{16}$ This is distinct from the Indian-filing pattern and fibrosis in $\mathrm{CeC}$. To assess disease metastasis, imaging modalities can be used, such as computed tomography and bone scans, as well as positron emission tomography/computed tomography. ${ }^{17}$
There is no consensus on treatment for $\mathrm{CeC}$ due to the small number of cases, but modalities used include chemotherapy, snake venom, radiotherapy, hyperthermia, and hormonal antagonists. ${ }^{2,18-20}$ One patient with primary $\mathrm{CeC}$ improved with only tamoxifen therapy, suggesting that hormonal therapy may be sufficient to control estrogen receptor-positive disease. ${ }^{2}$ After treatment with eribulin, our patient had softening of her nodules, which appears to be the first documented case in $\mathrm{CeC}$. Yet, treatment remains focused on symptom palliation and improving quality of life, because it is never curative.

\section{ACKNOWLEDGMENTS}

The authors thank Margaret Hinshelwood, $\mathrm{PhD}$, for her assistance in preparation of this article.

ORCID

David M. Metter (D) http://orcid.org/0000-0001-9114-7400

John E. Pippen (iD http://orcid.org/0000-0003-3522-9780

1. Lookingbill DP, Spangler N, Sexton FM. Skin involvement as the presenting sign of internal carcinoma. A retrospective study of 7316 cancer patients. J Am Acad Dermatol. 1990;22(1):19-26. doi:10.1016/ 0190-9622(90)70002-Y.

2. Siddiqui MA, Zaman MN. Primary carcinoma en cuirasse. J Am Geriatr Soc. 1996;44(2):221-222.

3. Brownstein MH, Helwig EB. Spread of tumors to the skin. Arch Dermatol. 1973;107(1):80-86.

4. Senn N. The Pathology and Surgical Treatment of Tumors. Philadelphia, PA: W.B. Saunders; 1895.

5. Handley W. The pathology of cancerous pachydermia (so-called cancer "en cuirasse"). In: Handley W, ed. Cancer of the Breast and Its Treatment, 2nd ed. Middlesex, England: Middlesex Hospital Press; 1922.

6. Velpeau A. A Treatise on the Diseases of the Breast and Mammary Region, Vol. 344. London: The Sydenham Society; 1856.

7. Siegel RL, Miller KD, Jemal A. Cancer statistics, 2018. CA Cancer J Clin. 2018;68(1):7-30. doi:10.3322/caac.21442.

8. Brownstein MH, Helwig EB. Patterns of cutaneous metastasis. Arch Dermatol. 1972;105(6):862-868.

9. Sittart JA, Senise M. Cutaneous metastasis from internal carcinomas: a review of 45 years. An Bras Dermatol. 2013;88(4):541-544. doi: 10.1590/abd1806-4841.20131165.

10. Alcaraz I, Cerroni L, Rutten A, Kutzner H, Requena L. Cutaneous metastases from internal malignancies: a clinicopathologic and immunohistochemical review. Am J Dermatopathol. 2012;34(4):347-393. doi:10.1097/DAD.0b013e31823069cf.

11. Schoenlaub P, Sarraux A, Grosshans E, Heid E, Cribier B. Survival after cutaneous metastasis: a study of 200 cases. Ann Dermatol Venereol. 2001;128(12):1310-1315.

12. Mordenti C, Concetta F, Cerroni M, Chimenti L. Cutaneous metastatic breast carcinoma: a study of 164 patients. Acta Dermatoven APA 2000;9(4):143-148.

13. Lin JH, Lee J, Chao SC, Tsao CJ. Telangiectatic metastatic breast carcinoma preceded by en cuirasse metastatic breast carcinoma. Br J Dermatol. 2004;151(2):523-524. doi:10.1111/j.1365-2133.2004.06140.x.

14. Mullinax K, Cohen JB. Carcinoma en cuirasse presenting as keloids of the chest. Dermatol Surg. 2004;30(2 Pt 1):226-228. 
15. Whitaker-Worth DL, Carlone V, Susser WS, Phelan N, Grant-Kels JM. Dermatologic diseases of the breast and nipple. J Am Acad Dermatol. 2000; 43(5 Pt 1):733-751. quiz 752-734. doi:10.1067/mjd.2000.109303.

16. Fett N, Werth VP. Update on morphea: part I. Epidemiology, clinical presentation, and pathogenesis. J Am Acad Dermatol. 2011;64(2): 217-228. quiz 229-230. doi:10.1016/j.jaad.2010.05.045.

17. Win AZ, Aparici CM. Carcinoma en cuirasse from recurrent breast cancer seen on FDG-PET/CT. J Clin Imaging Sci. 2015;5:35. doi: 10.4103/2156-7514.159456.

18. Vernon CC, Hand JW, Field SB, et al. Radiotherapy with or without hyperthermia in the treatment of superficial localized breast cancer: results from five randomized controlled trials. International Collaborative Hyperthermia Group. Int J Radiat Oncol Biol Phys. 1996;35(4):731-744.

19. Costa LA, Miles H, Araujo CE, Gonzalez S, Villarrubia VG. Tumor regression of advanced carcinomas following intra- and/or peritumoral inoculation with VRCTC-310 in humans: preliminary report of two cases. Immunopharmacol Immunotoxicol. 1998;20(1):15-25. doi:10.3109/08923979809034806.

20. Reich A, Samotij D, Szczech J, Wozniak Z, Szepietowski J. Carcinoma en cuirasse as an initial manifestation of inflammatory breast cancer. PDIA. 2016;33(2):142-145. doi:10.5114/pdia.2015. 48069 .

\section{Avocations}

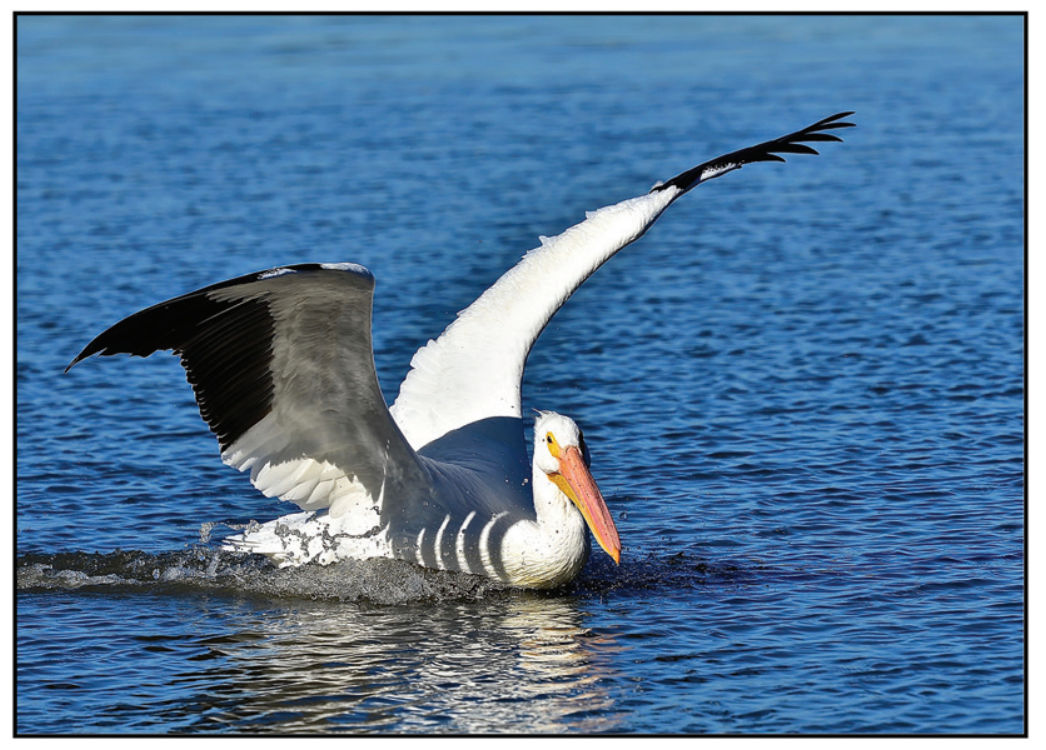

"American White Pelican." Photo taken at White Rock Lake in Dallas, Texas. Copyright (C) Rolando M. Solis, MD. Dr. Solis is co-medical director of the Cardiopulmonary Rehabilitation Program at Baylor Scott \& White Heart Hospital Plano, Plano, Texas (e-mail: rmsolis@mac.com). 